\title{
Biological durability of injection moulded wood plastic composite boards.
}

\begin{abstract}
The steadily growth of Wood Plastic Composite (WPC) in exterior applications resulted a need to understand their durability. In Malaysia, the durability of WPC is not only affected by mold and decay fungi as biodegradation agents but also due the termites attack. Therefore, this study was carried out to investigate the durability of WPC produced from different wood fine loadings $(60,65$ and $70 \%)$ and MAPP $(1,2,3$ and 4\%) concentration. The aim of this study is to determine the optimum WPC formulation associate with higher durability against biodegradation agents. Commercial polypropylene, wood fines and coupling agent premixed in dumper mixer for $30 \mathrm{~min}$ prior to extrusion process at temperature of $190^{\circ} \mathrm{C}$ using $110 \mathrm{~mm}$ counter-rotating twin-screw extruder. The premixed raw materials were then subjected to injection moulded using 40 ton press moulding machine and pressed into size of $30 \mathrm{~mm} \times 30$ $\mathrm{mm}$ and $3 \mathrm{~mm}$ thick board. Biological durability tests were carried out according to ASTM D4445 for mold, ASTM method D 2017 for decay fungi and ASTM D 3345 for termites. From the result, $70 \%$ wood fine loading showed significantly lower durability due to the insufficient encapsulation of wood fine with polymer matrix. Higher percentage of coupling agent (MAPP) used in the WPC boards will provide higher durability of WPC. Conclusively, the optimum formulation for WPC i.e., 4\% MAPP and $60 \%$ wood fine loading gave the highest protection against mold, decay fungi and termites.
\end{abstract}

Keyword: Wood plastic composite; Wood fine loading; Termites; Mold decay fungi. 